University of Nebraska - Lincoln DigitalCommons@University of Nebraska - Lincoln

To Improve the Academy

Professional and Organizational Development

Network in Higher Education

1984

\title{
Year-long Faculty Discussion Groups: A Solution to Several Instructional Development Problems
}

\author{
L. Dee Fink
}

Follow this and additional works at: http://digitalcommons.unl.edu/podimproveacad

Part of the Higher Education Administration Commons

Fink, L. Dee, "Year-long Faculty Discussion Groups: A Solution to Several Instructional Development Problems" (1984). To Improve the Academy. 53.

http://digitalcommons.unl.edu/podimproveacad/53

This Article is brought to you for free and open access by the Professional and Organizational Development Network in Higher Education at DigitalCommons@University of Nebraska - Lincoln. It has been accepted for inclusion in To Improve the Academy by an authorized administrator of DigitalCommons@University of Nebraska - Lincoln. 


\section{Year-long Faculty Discussion Groups: A Solution to Several Instructional Development Problems}

\section{Dee Fink}

University of Oklahoma

People trying to establish an instructional development program on a college or university campus frequently face two major problems. One of these is simply the difficulty of acquainting the faculty with and interesting them in an activity that is generally not familiar to them. Compounding this problem is the not uncommon belief among faculty members that participating in something called instructional development is tantamount to admitting that they have a problem with their teaching, i.e., a "professional disease" that they cannot solve by themselves.

A second type of difficulty is the limited capacity of the instructional development person to respond to all kinds of teaching problems. Presumably the person filling this role has some degree of teaching experience and training in the analysis of teaching-learning problems. Nonetheless, given the short history of instructional development programs, few people have a large amount of training specifically for this role; most of us have evolved into it from other roles. Hence we sometimes find ourselves hard pressed to come up with good solutions to the problems that faculty members bring to us.

This paper describes a program activity - the use of year-long 
faculty discussion groups - that has worked effectively for the author in addressing both the problems described above and that seems to have a number of other values as well.

Year-Long Faculty Discussion Groups: What They Are. The key characteristic that distinguishes this activity from other activities common in instructional development programs is the fact that the groups are set up in such a way that the participants become members of a quasi-permanent group, i.e., one that has a constant membership and that meets repeatedly as a special group for one whole academic year.

This differentiates these groups from such things as brown-bag colloquia where, even though a person may attend more than once, there is no sense of membership or belonging, and hence no commitment to the work of the group.

The discussion groups are also different from workshops in that, even though both are task-oriented, workshops are generally one-shot efforts. Consequently they suffer from the same problem as religious revivals: although the experience may be very powerful at the time, the effect on one's behavior falls off with time because there is no continuity of contact with the source of the change. In the faculty discussion groups, faculty members meet 10 to 12 times a year, and many faculty members voluntarily choose to participate again in subsequent years.

Faculty Discussion Groups: How They Work. The groups are set up and operate in the following way. During the second week of classes in the fall, a letter is sent to all faculty members describing the discussion groups and asking those professors who are interested to send their names back to me. The letter also indicates what types of groups are being organized and which days of the week each group will meet. (The different types are described below).

After the replies have been received, I assemble the participants into groups of approximately $\mathbf{1 5}$ faculty and then set up the time and place of the first meeting. There have been four or five groups each year since the program was established.

Each group meets on a weekday from noon until 1:30. There is a meal served in the union followed by one hour of discussion on some aspect of college teaching. 
At the first meeting the participants introduce themselves and comment on what prompted them to join the group, i.e., what they hope to get out of the discussions. The participants then "brainstorm" a list of topics for possible discussion at various meetings throughout the year. After a sizable list has been generated, a selection is made for the first few topics.

From that meeting on, my responsibilities are (1) to obtain the necessary resources for the discussion of a given topic (e.g., articles, guest speakers, institutional data), (2) to send out reminders for the next meeting, and (3) to serve as discussion moderator at the meetings. In a few instances I will in essence be the "visiting expert" for the day. But more commonly my role is to make sure everyone has a chance to participate in the discussion, to keep the discussion focused and moving, and - when possible - to press for a summary and conclusion near the end.

During the first four years of operation, three types of groups have evolved. The most popular have been those with a varied agenda. Different topics are discussed every time, with choice of topic done by group consensus. Groups have discussed a wide range of topics, but some representative examples are teaching students how to think, student evaluations, test construction, general education curriculum, and teaching students how to study.

A second type of group stays with a single topic for the whole year. When selecting such topics, I have taken care to choose subjects that will sustain productive discussion for that long a period of time. Topics that have been used with success thus far are "How to Teach Subject Matter That Involves Creativity", "How to Design a new Course", "Computers in College Teaching", and "Improving your Lectures".

The third type of group is smaller and more clinical in nature, its topic has been "Analyzing Your Own Teaching". There are five to seven people in each of these groups. After a discussion of appropriate procedures, the members of these groups set up a schedule to visit each other's classes. The person to be observed provides some materials (e.g., course syllabus) and comments about his or her course, i.e.,the person talks about what he or she is trying to accomplish, and identifies any special questions he has about his or her own teaching. During the 
next two weeks, each person in the group visits that person's class. At the next meeting, the members describe what they saw that they liked and what they thought could be improved. These groups were initially set up to give faculty members feedback from peers (outside their own department) on their classroom teaching skills. As valuable as this was, the participants have consistently said that they find as much or more value in the chance to observe and discuss the teaching of other professors.

Faculty Response to the Discussion Groups. The faculty response to the groups has been strong. The first year I issued the general invitation to join them, I hoped there would be enough to form one group with 15 people in it. In fact, there were 70 responses, equal to 8 percent of the entire faculty. The level of participation since then has remained fairly constant at 60 to 70 people per year. This number typically includes 30 to 35 people who are joining one of these groups for the first time and $\mathbf{3 0}$ to $\mathbf{3 5}$ who have been members previously. After four and one-half years, over 200 faculty members-approximately 25 percent of the entire faculty-have participated in this activity for at least one year; of this group, 75 have participated for two or more years.

The spectrum of participation has been broad in terms of both academic area and years of teaching experience. There have been participants from every college on campus and nearly every department. The level of teaching experience has also been quite representative. Approximately one-third have been teaching for five years or less, another third for more than 15 years, and the other third between five and fifteen years.

At the end of each year when I ask the participants to describe the value of their participation in the groups, they mention several benefits. One is the morale effect. At a large comprehensive university like this one, faculty members say they often feel that teaching does not count for much. But when they are able to meet every two weeks with a sizable group of professors who are clearly committed to improving their teaching, their own desire to teach well is given social support. In one person's words, "I leave each meeting a little more charged up to do better."

A second value is the intended one: they get some new and better 
ideas about teaching. These ideas come from several sources: the articles, the visitors, the other members of the group, their own thinking stimulated by the discussions, and-less frequently-from myself as the university's Instructional Consultant.

The third effect is more professional development than instructional development per se. On a large campus like the University of Oklahoma, the faculty is organized into eight colleges with 48 individual academic units located in 30 separate buildings. One bad consequence of this "division of labor" is that faculty members seldom find themselves in situations that make them feel like they are part of the whole university. Ordinarily they spend all day every day working entirely within a departmental context, if not within their own office or lab. But attending the faculty discussion groups allows them to sit down next to, have a meal with, and talk with a nuclear physicist one week, a music composer the next week, a meteorologist, a sociologist, and so on. In the words of one person, "This is the kind of intellectual exchange that attracted me to academic life in the first place, but this is the first time I've experienced it since I've been here."

An additional benefit for the instructional development program is that people who have participated for a year or more in one of these groups are much more aware of and ready to participate in other instructional development activities when they occur.

Directing the Discussion Groups. Directing one or more discussion groups as described above requires the usual and expected kinds of organizational activity: sending out the initial invitations, sorting participants into groups, reserving meeting rooms, selecting menus, keeping a record of meal payments, finding the necessary resources (articles, visitors), sending out meeting reminders, and then actually leading the discussions.

Trying to be an effective director of a program like this is challenging in several ways. First, one must be capable of earning the respect of the faculty intellectually. This means being able to go beyond superficials to dealing with fundamental problems, issues, and ideas. Second, one needs to be adept at leading group discussions, especially with faculty members. This means knowing how to build a climate of trust and openness as well as how to handle overly talkative individuals. It also involves knowing when to drop out of the discus- 
sion in order to let it run itself and when to step in to clarify an issue or to start pulling the loose ends together. When these groups first began, the members were helpful in informing me when I was exerting too much or too little leadership.

The third requirement is the ability to listen well. The leader of a program like this needs to be very sensitive to the situation and needs of faculty members both individually and collectively. If one wants to respond correctly or to initiate an effective activity, one has to "hear" correctly.

The fourth demand is to know the resources available for learning about teaching. They include pertinent literature, individual teachers on campus, and other information and services within the institution. These can then be linked to groups or individuals with particular questions or needs.

Operational Suggestions. For anyone considering such a program, there are a few "lessons learned" that can be passed along.

One key factor is the frequency of the meetings: do not meet too frequently. Faculty members have busy schedules and cannot afford an additional activity that takes too much time. Meeting for a hour and a half every other week has worked out well. Attendance has consistently averaged 70 percent.

The sorting of people into groups is critical. As far as possible, I avoid putting people from the same department into the same group. This keeps departmental politics from reducing the openness of the discussions or, conversely, avoids the formation of sub-group cliques. It also maximizes the opportunity to meet people with very different backgrounds and occasionally novel ideas.

One observation on group membership: for reasons I do not fully understand, groups with several female members tend to be more cohesive and productive than groups with few or no women in them. I have no control over the number of female faculty members who sign up for these groups; but to the degree possible, I try to distribute the number of women as evenly as I can in each group.

The final suggestion concerns payment for meals. Since the program began, the participating members have paid for a major portion of their meals. This approach appears to provide them with a sense of ownership and investment in the groups. As a result they seem 
to be somewhat more committed to making the groups enjoyable and productive.

Conclusions. People who want to encourage faculty members to spend more time thinking and learning about college teaching should consider the use of permanent discussion groups. The dynamics of relatively small groups with a stable membership can build a sense of identity and community that gives them an advantage over ad hoc participation in workshops or open (and usually anonymous) colloquia.

One reflection of the value of this activity is the level of participation in the program at the University of Oklahoma. In four and one-half years of operation, over $\mathbf{2 0 0}$ faculty members have participated in these discussion groups, a number equal to approximately 25 percent of the entire faculty. Nearly 40 percent of this group has participated two or more years. This has occurred in an organization where the faculty have a very heavy teaching and research responsibilities, where participation is voluntary, and where they have to pay most of the cost of their own meals in order to participate.

Their decision to become involved and to continue participating ultimately depends on whether they perceive the activity to be meaningful or not. The level of participation, the quality of the discussions, the written comments at the end of the year, and occasional comments from their chairpersons indicate that many of the professors are in fact re-thinking their ideas on educational questions and are finding new methods of teaching to try in the classroom. 